\title{
Reactive magnetron sputtering deposition of bismuth tungstate onto titania nanoparticles for enhancing visible light photocatalytic activity
}

Marina Ratova ${ }^{1 *}$, Peter J. Kelly ${ }^{1}$, Glen T. West ${ }^{1}$, Lubomira Tosheva ${ }^{2}$, Michele Edge $^{2}$

1 Surface Engineering Group, Manchester Metropolitan University, Manchester, M1 5GD

2 School of Science and the Environment, Manchester Metropolitan University, Manchester, M1 5GD

* Corresponding author: M Ratova, School of Engineering, Manchester Metropolitan University, John Dalton Building, Chester Street, Manchester M1 5GD, UK, tel. +44 161247 4648, e-mail address marina ratova@hotmail.com

\begin{abstract}
Titanium dioxide - bismuth tungstate composite materials were prepared by pulsed DC reactive magnetron sputtering of bismuth and tungsten metallic targets in argon/oxygen atmosphere onto anatase and rutile titania nanoparticles. The use of an oscillating bowl placed beneath the two magnetrons arranged in a co-planar closed field configuration enabled the deposition of bismuth tungstate onto loose powders, rather than a solid substrate. The atomic ratio of the bismuth/tungsten coatings was controlled by varying the power applied to each target. The effect of the bismuth tungstate coatings on the phase, optical and photocatalytic properties of titania was investigated by by X-ray diffraction, energy-dispersive X-ray spectroscopy (EDX), Brunauer-EmmettTeller (BET) surface area measurements, transmission electron microscopy (TEM), UV-visible diffuse reflectance spectroscopy and an acetone degradation test. The latter involved measurements of the rate of $\mathrm{CO}_{2}$ evolution under visible light irradiation of the photocatalysts, which indicated that the deposition of bismuth tungstate resulted in a significant enhancement of visible light activity, for both anatase and rutile titania particles. The best results were achieved for coatings with a bismuth to tungsten atomic ratio of 2:1. In addition, the mechanism by which the photocatalytic activity of the $\mathrm{TiO}_{2}$ nanoparticles was enhanced by compounding it with bismuth tungstate was studied by microwave cavity perturbation. The results of these tests confirmed that such enhancement of the photocatalytic properties is due to more efficient photogenerated charge carrier separation, as well as to the contribution of the intrinsic photocatalytic properties of $\mathrm{Bi}_{2} \mathrm{WO}_{6}$.
\end{abstract}

\section{Keywords}

Photocatalyst; titanium dioxide; bismuth tungstate; visible light responsive; magnetron sputtering 


\section{Introduction}

The presence of volatile organic compounds (VOCs) in the ambient air is a major environmental concern. As the level of pollution may vary significantly depending on the location, the choice of depollution method presents an important task [1]. Photocatalytic depollution is proven to be a process that could potentially replace conventional methods of VOCs destruction; through the process of photocatalytic oxidation, it leads to the formation of simple and nontoxic end products, such as $\mathrm{H}_{2} \mathrm{O}$ and $\mathrm{CO}_{2}$. Consequently, the capability of photocatalytic materials in VOC destruction is often used for testing their efficiency as photocatalysts. Of the model VOCs pollutants, photocatalytic materials are most frequently tested for their ability to destruct acetone [1-5], formaldehyde [6], methanol[1, 7], benzene[5, 8], phenol[9, 10] and toluene[5, 9, $11,12]$.

Of the known photocatalytic materials, titanium dioxide, or titania, in anatase form is typically the photocatalyst of choice for various environmental remediation processes, due to its low cost, chemical stability and low toxicity. However, $\mathrm{TiO}_{2}$ possesses some remarkable drawbacks often mentioned in the literature. Thus, the relatively high band gap value of $\mathrm{TiO}_{2}(3.2 \mathrm{eV}$ for the anatase phase) means that only the UV part of the spectrum (around 4\% of sunlight) can be used for its activation. Moreover, titanium dioxide is characterised with low separation efficiency of photoexcited charge carriers, which makes its use a rather challenging task for real industrial waste management. Various strategies for the modification of titanium dioxide have been proposed to date, with doping with transition metals [13-15] and non-metallic [15, 16] elements being the most conventional methods. However, the photocatalytic activity of modified materials is often not comparable with that of unmodified $\mathrm{TiO}_{2}$, due to higher rates of photogenerated charge carrier recombination.

Coupling titanium dioxide with narrow band semiconductors is a method currently being widely explored; it typically results in enhancement of optical abilities of the material, as well as improved separation of photogenerated charge carriers. Thus, titanium dioxide is reported as having been coupled with such materials, as $\mathrm{CdS}$ [17], $\mathrm{WO}_{3}$ [18], $\mathrm{Cu}_{2} \mathrm{O}[19]$, etc. Bismuth tungstate $\left(\mathrm{Bi}_{2} \mathrm{WO}_{6}\right.$ ) is gaining increasing popularity as a narrow band gap semiconductor that exhibits good photocatalytic properties under visible light irradiation $[20,21]$. Several successful attempts to couple bismuth tungstate with titanium dioxide have been reported recently. The main preparation methods described are a hydrothermal method [10, 22-24], electrospinning [25, 26] and dip-coating [27]. Synergistic effects between $\mathrm{TiO}_{2}$ and $\mathrm{Bi}_{2} \mathrm{WO}_{6}$ are reported to promote more efficient separation of photogenerated electrons and holes [24], as well as introducing visible light activity to the composite material, as $\mathrm{Bi}_{2} \mathrm{WO}_{6}$ can be excited by visible light and its photogenerated holes can move to the valence band of $\mathrm{TiO}_{2}$.

Magnetron sputtering represents a well-established technique for the deposition of metallic and ceramic coatings onto various substrates [28]. It has been shown recently that reactive co-sputtering of bismuth and tungsten targets can be used for the deposition of visible light-active photocatalytic bismuth tungstate coatings [29]. Magnetron sputtering, though, is not typically used for deposition onto powders, due to the difficulty of achieving uniform coverage from a 
predominately "line of sight" process. However, the use of an oscillating bowl taken from a vibrating bowl feeder mechanism [30] enables the deposition of materials onto nanoparticulates in a single stage process. The bowl oscillates vertically, but springs connected between the electromagnet and the base plate are designed to also impart a lateral moment to the oscillation. The resulting motion causes particles in the bowl to roll or hop in a circular path around the bottom of the bowl, underneath a pair of magnetrons. In the present work, magnetron sputtering from a dual source was used to deposit bismuth tungstate onto titanium dioxide anatase and rutile nanoparticulates, which were oscillated in the bowl positioned under the magnetrons. This is a new technique, and to the best of our knowledge, reactive co-sputtering of bismuth and tungsten from metallic targets onto titania nanoparticulates has not been previously reported elsewhere in the literature.

The present study, therefore, describes the deposition of bismuth tungstate onto commercially available titanium dioxide nanoparticles (Crystal Global PC500 and Sigma Aldrich rutile titania) and the testing of the materials for their ability to degrade acetone as a model VOC compound (and one of the most important air pollutants [31]). Charge carrier dynamics of the titania powders before and after coating was studied with a microwave cavity perturbation method $[32,33]$.

\section{Materials and methods}

\subsection{Deposition}

The bismuth tungstate coatings were deposited in a single stage process in a vacuum coating system that included two $300 \mathrm{~mm} \times 100 \mathrm{~mm}$ planar unbalanced type II magnetrons [28] installed on the top of the chamber facing the oscillator bowl in a closed field configuration. The schematic representation of the setup if given in the Figure 1. The bismuth target was fitted to one of the magnetrons, and the tungsten target to the other one (both targets were $99.5 \%$ purity and bonded to copper backing plates). The targets were sputtered in reactive mode in an argon/oxygen atmosphere, at a partial pressure of $0.4 \mathrm{~Pa}$. The flow of gases was controlled with mass flow controllers (10 sccm of $\mathrm{Ar}$ and $20 \mathrm{sccm}$ of $\mathrm{O}_{2}$ ). The magnetrons were powered in pulsed DC mode using a dual channel Advanced Energy Pinnacle Plus power supply; a pulse frequency of $100 \mathrm{kHz}$ and duty of $50 \%$ (synchronous mode) were used for all the deposition runs. The powers applied to the targets were varied to vary the Bi/W content in the films (100200W for the Bi target and 400-450W for the W target).

For each run, a $10 \mathrm{~g}$ charge of titania particles was loaded into the bowl, and then the chamber was evacuated to a base pressure of lower than $1 \times 10^{-3} \mathrm{~Pa}$. The particles used were PC500 anatase titania from Crystal Global (particle size 5-10 $\mathrm{nm})$; an additional set of identical coatings was also deposited onto rutile titania (Sigma Aldrich) with a particle size of $\leq 100 \mathrm{~nm}$. The deposition time was 1 hour for all the coatings studied. 


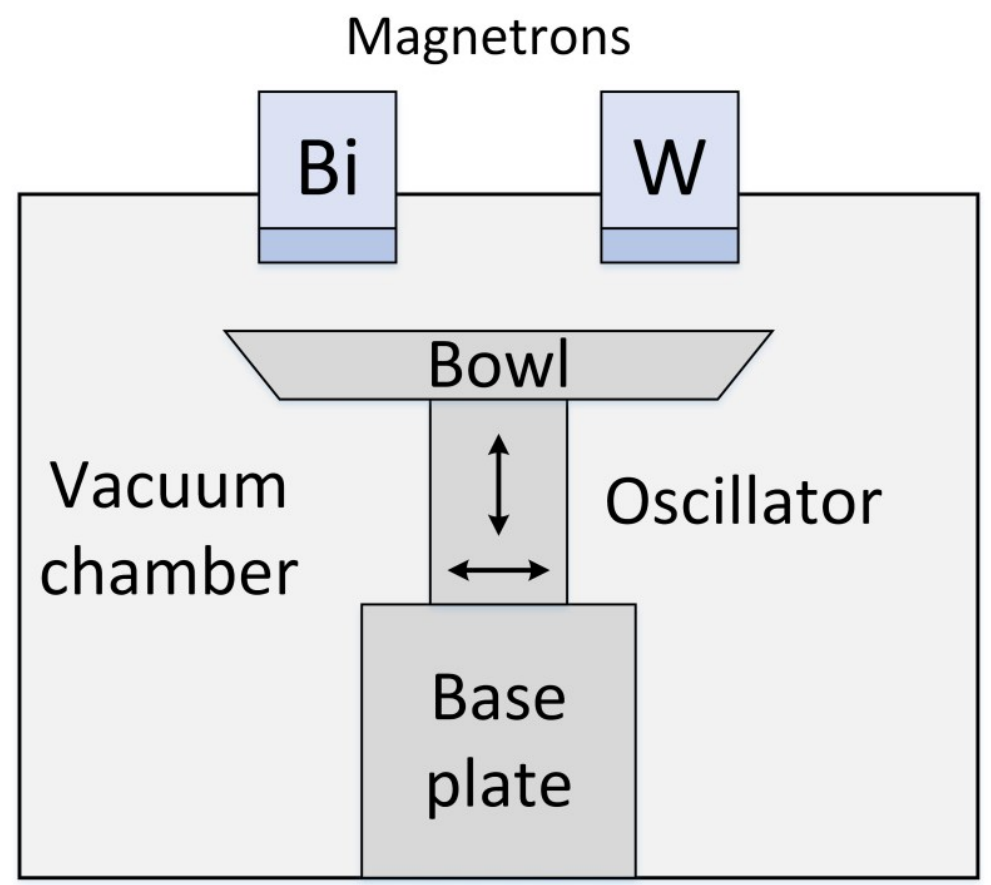

Figure 1. Schematic representation of powder coating sputtering rig in dual co-planar configuration

\subsection{Characterization}

The X-ray diffraction patterns of the samples were obtained using a Panalytical Xpert diffractometer with $\mathrm{CuK} \alpha 1$ radiation at $0.154 \mathrm{~nm}$ over the range 20 to 70 o20; the accelerating voltage and applied current were $40 \mathrm{kV}$ and $30 \mathrm{~mA}$, respectively. The composition of the powders was determined using EDX (EDAX - Trident on Zeiss Supra 40 FEGSEM). The specific surface areas of the materials were determined with Brunauer-Emmett-Teller (BET) surface area measurements, which were made using a Micromeritics ASAP 2020 system. Samples were heated for $12 \mathrm{~h}$ at $300^{\circ} \mathrm{C}$ prior to analysis and surface areas were calculated from nitrogen adsorption data in the range of relative pressures between 0.05 and 0.3 using the BET model. Optical properties of the materials were determined from UV-visible diffuse reflectance spectra recorded with an Ocean Optics USB4000 spectrometer equipped with a diffuse reflectance probe. Selected samples have been analysed with TEM (FEI Tecnai FEGTEM Field Emission gun TEM/STEM fitted with HAADF detector, FEI, Cambridge, UK).

\subsection{Photocatalytic activity assessment (acetone degradation test)}

The photocatalytic activities of the powders were assessed using an acetone degradation test. The degradation of acetone was performed in purpose-built reaction cell equipped with a quartz glass window. The fixed amount of photocatalyst was evenly spread over a $55 \mathrm{~mm}$ glass plate and placed into the reaction cell; $1 \mathrm{ml}$ of liquid acetone was introduced to the cell with a syringe. The amount of photocatalyst was varied, depending on the substrate used, to get a detectable response during a 1 hour experiment. For this work $1 \mathrm{~g}$ of the anatase powders and $10 \mathrm{~g}$ of the rutile powders were used for each measurement. The photocatalytic decomposition process of acetone can be summarised using the following equation: 


$$
\mathrm{C}_{3} \mathrm{H}_{6} \mathrm{O}+4 \mathrm{O}_{2} \underset{\mathrm{hv>3.2 \textrm {eV }}}{\stackrel{\mathrm{TiO}_{2}}{\longrightarrow}} 3 \mathrm{CO}_{2}+3 \mathrm{H}_{2} \mathrm{O}
$$

$\mathrm{A} \mathrm{CO}_{2}$ detector (Vaisala CARBOCAP® carbon dioxide meter used with a Vaisala GM70 2000 ppm probe) was incorporated into the reaction cell. The reaction cell was kept in the dark for $30 \mathrm{~min}$ at room temperature to reach the adsorptiondesorption equilibrium, then irradiated with the simulated visible light source for a total time of $1 \mathrm{~h}$. The visible light source was simulated by combining a fluorescent lamp (Sunlite 8W white LED) with a 395nm long-pass filter (Knight Optical, UK). The emission spectrum of the irradiation source used for photocatalytic testing was recorded with an Ocean Optics USB400 spectrometer and is presented in Figure 2.

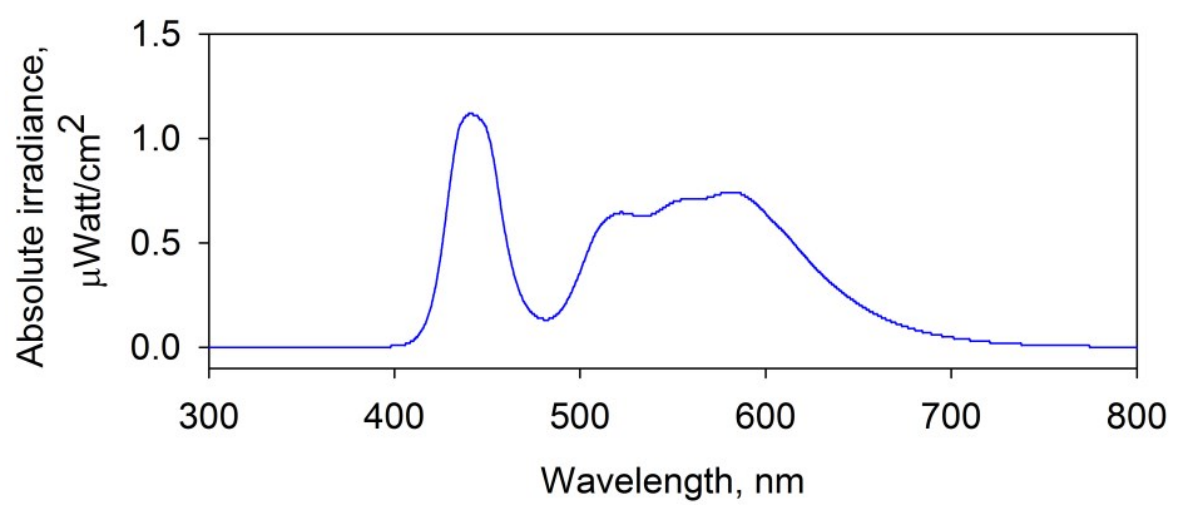

Figure 2. Spectrum of the fluorescent light source used for photocatalytic testing (with UV filter)

2.4. Charge carrier dynamics study (microwave cavity perturbation) The dynamics of the photogenerated charge carriers were studied using a microwave cavity perturbation method. This technique provides a simple and contactless method for qualitative study of charge carrier dynamics. Microwaves are directed via the waveguide through an aperture into a cavity. Placing the photocatalytic sample into the cavity and exposing it to UV/visible irradiation results in a shift of the resonant frequency position and attenuation of the microwave power. The time dependence of the attenuation of the microwave power provides a profile of the production of free charge carriers [32, 34]. This phenomenon takes place due to the production of heat (phonons) by free carriers, which in turn reduces the ability of the cavity to store energy [34]. Upon switching off the light the charge carriers recombine.

Microwave measurements were carried out using a Marconi IFR 6823 programmable scalar analyser connected to a rectangular waveguide and cylindrical cavity. The detailed description of the setup is given elsewhere [33]. Powdered samples $(2.0 \mathrm{~g})$ were placed to the cavity and irradiated with the same light source as used for the acetone degradation test described earlier (with a $395 \mathrm{~nm}$ long pass filter).

\section{Results and discussion}

\subsection{Coatings overview}


A summary of the deposition conditions, and compositional properties of the coatings measured by EDX are summarised in Table 1.

Table 1. Overview of deposition conditions and elemental ratios of coated and uncoated titania powders

\begin{tabular}{|l|l|l|l|l|l|}
\hline Sample ID & Substrate & $\begin{array}{l}\text { Power on } \\
\text { Bi target, } \\
\text { W }\end{array}$ & $\begin{array}{l}\text { Power on } \\
\text { W target, } \\
\text { W }\end{array}$ & $\begin{array}{l}\text { At. \% Ti / } \\
\text { at. \% Bi / } \\
\text { at. \% W }\end{array}$ & Bi/W ratio \\
\hline A0 & $\begin{array}{l}\text { Anatase } \\
\text { (PC500) }\end{array}$ & - & - & $100 / 0 / 0$ & - \\
\hline A1 & $\begin{array}{l}\text { Anatase } \\
(\text { PC500) }\end{array}$ & 200 & 400 & $89 / 9 / 2$ & $4.5 / 1$ \\
\hline A2 & $\begin{array}{l}\text { Anatase } \\
\text { (PC500) }\end{array}$ & 150 & 450 & $88 / 8 / 4$ & $2 / 1$ \\
\hline A3 & $\begin{array}{l}\text { Anatase } \\
(\text { PC500) }\end{array}$ & 120 & 480 & $90 / 5 / 5$ & $1 / 1$ \\
\hline R0 & Rutile & - & - & $100 / 0 / 0$ & - \\
\hline R1 & Rutile & 200 & 400 & $92 / 8 / 2$ & $4 / 1$ \\
\hline R2 & Rutile & 150 & 450 & $88 / 8 / 4$ & $2 / 1$ \\
\hline R3 & Rutile & 120 & 480 & $88 / 6 / 6$ & $1 / 1$ \\
\hline
\end{tabular}

As can be seen from the results presented in Table 1, the deposition of bismuth and tungsten oxides onto anatase and rutile powders resulted in coatings with very similar compositions under identical deposition conditions. The results of EDX elemental mapping (not given here) revealed that both bismuth and tungsten were distributed evenly across the surface of the titania powders, with no visual difference between the two powder types. It is known that bismuth is characterised with a relatively high sputtering yield due to polyatomic sputtering [35]; this was confirmed earlier for the deposition of bismuth complex oxides $[29,36]$ onto flat substrates. The EDX data presented in Table 1 also confirms that the sputtering yield of bismuth is considerably higher than that of tungsten; thus, ratios of powers applied to the bismuth and tungsten targets of 1:2, 1:3 and 1:4 resulted in $\mathrm{Bi} / \mathrm{W}$ ratios in the coatings of 4.5:1, 2:1 and $1: 1$.

\section{2. $\quad \mathrm{X}$-ray diffraction (XRD)}

X-ray diffraction was used to characterize the phase structure of coated and uncoated titania particles. The XRD spectra of the coatings are given in Figure 3 a-b. As evidenced from the XRD patterns, all the diffraction patterns can be indexed to the corresponding phase of the titanium dioxide substrate only. Thus, for anatase titania major peaks were found at $25.3^{\circ}, 37.8^{\circ}, 48.0^{\circ}, 55.1^{\circ}$ and $62.7^{\circ}$ (JCPDS: 21-1272). Rutile powders exhibited characteristic rutile peaks at $27.4^{\circ}$, $36.1^{\circ}, 41.2^{\circ}, 44.1^{\circ}, 54.3^{\circ}, 56.6^{\circ}, 62.7^{\circ}$ and $64.0^{\circ}$ (JCPDS: $21-1276$ ). The absence of bismuth tungstate peaks of the XRD patterns can be explained by the low fraction of the coatings within the sample, compared to the titania, along with a weaker diffraction response could be the cause of a pure titania XRD patterns. 

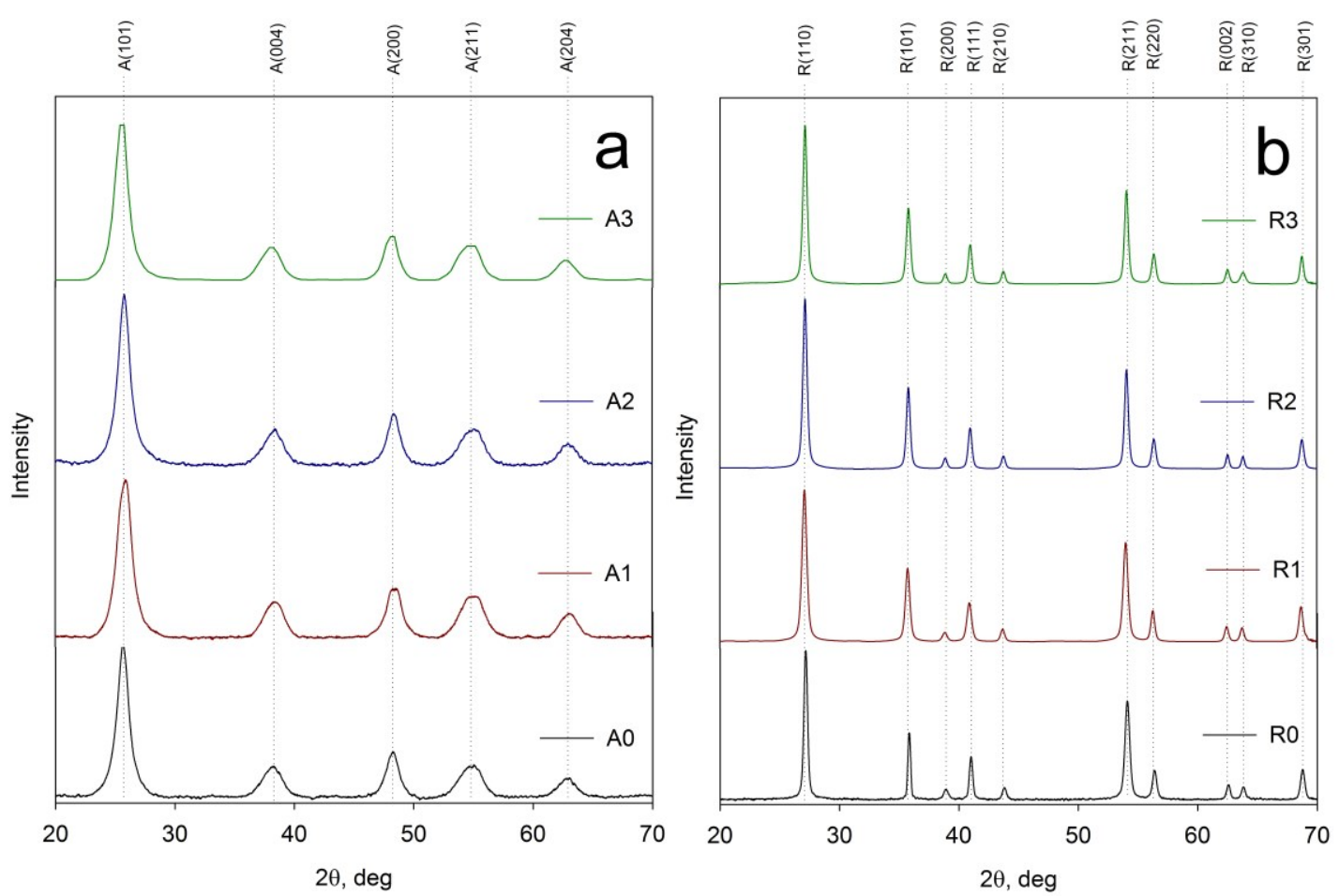

Figure 3. XRD patterns of bismuth tungstate-coated and uncoated titania samples; a - anatase PC500 titania substrate; $b$ - rutile titania substrate

\subsection{Brunauer-Emmett-Teller (BET) surface area}

The surface areas of the samples were determined by $\mathrm{N}_{2}$ adsorption / desorption using the Brunauer-Emmett-Teller (BET) method. The surface areas values are given in the Table 2. It should be noted that surface areas of the anatase powders were approximately 10 times higher than those of the rutile powders. This fact has been considered by the authors when testing and discussing the photocatalytic performance of the materials. Essentially, due to the difference in surface areas, the photocatalytic responses of the two different titania powder types should not be compared directly.

Deposition of bismuth tungstate resulted in lower BET surface area values for either type of titania substrate used. In addition, the reduction in the surface area was greater as the ratio of Bi/W decreased, i.e., as the W content increased. Such reduction of the surface area is most likely due to the presence of tungsten oxide plates with low surface area in tungsten-rich samples.

Table 2. Surface area, band gap values and acetone degradation rate constants for coated and uncoated titania powders

\begin{tabular}{|c|c|c|c|c|}
\hline Sample ID & $\begin{array}{l}\text { BET surface } \\
\text { area, } \mathrm{m}^{2} / \mathrm{g}\end{array}$ & Band gap, eV & $\begin{array}{l}\text { Wavelength of } \\
\text { the light } \\
\text { required for } \\
\text { photoactivation, } \\
\text { nm }\end{array}$ & $\begin{array}{l}\text { Visible light } \\
\text { acetone } \\
\text { degradation } \\
\text { constant, min } \\
{ }^{1} \mathrm{~m}^{-2}\end{array}$ \\
\hline A0 & 345 & 3.20 & 387 & $1.08 \times 10^{-5}$ \\
\hline A1 & 314 & 3.04 & 408 & $2.81 \times 10^{-5}$ \\
\hline A2 & 309 & 2.99 & 415 & $5.56 \times 10^{-5}$ \\
\hline
\end{tabular}




\begin{tabular}{|l|l|l|l|l|}
\hline A3 & 263 & 2.97 & 417 & $4.52 \times 10^{-5}$ \\
\hline R0 & 30 & 3.12 & 397 & $0.53 \times 10^{-5}$ \\
\hline R1 & 30 & 3.01 & 412 & $1.31 \times 10^{-5}$ \\
\hline R2 & 29 & 2.99 & 415 & $1.83 \times 10^{-5}$ \\
\hline R3 & 28 & 2.99 & 415 & $1.30 \times 10^{-5}$ \\
\hline
\end{tabular}

\subsection{UV-visible diffuse reflectance spectroscopy}

Figures 4 a-b show the diffuse reflectance data for the anatase and rutile samples, respectively. The band gap values were calculated using Tauc plots of $[F(R) h v]^{0.5}$ versus hu, where $F(R)$ is the Kubelka-Munk function, and hu is the incident photon energy. The estimated values of the band gap are given in Table 2. It can be seen that band gap values of anatase PC500 and rutile particles are in good agreement with the literature band gap data, typically given as $3.2 \mathrm{eV}$ [37] and $3.1 \mathrm{eV}$ [38], respectively. The band gap of bismuth tungstate is typically reported to be 2.6-2.8 eV, depending on the production method $[39,40]$. The band gap of bismuth tungstate coatings deposited by pulsed DC reactive magnetron sputtering onto flat substrates is reported to be around $2.75 \mathrm{eV}$ [29]. It is obvious from the data that the deposition of bismuth tungstate resulted in significant band gap narrowing for both types of titania substrate used.
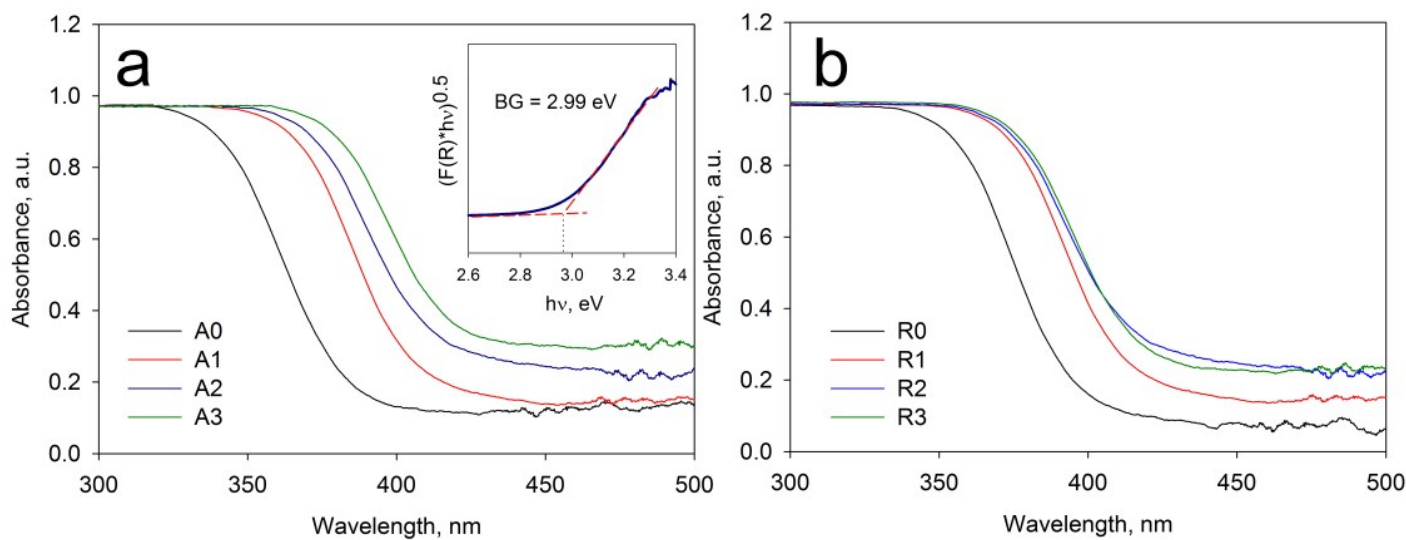

Figure 4. UV-visible absorbance spectra of bismuth tungstate-coated and uncoated titania samples; a - anatase PC500 titania substrate, $b$ - rutile titania substrate. Insert of the graph a shows an example of Tauc plot band gap calculation for sample A2.

\subsection{Transmission electron microscopy (TEM)}

The microstructures of plain and coated titania particles was further studied by TEM and high resolution TEM. The representative TEM images of bismuth tungstate-coated and uncoated anatase and rutile powders are given in Figures 5 a-f. Comparing uncoated anatase (Figure 5a) and rutile particles (Figure 5c) to the coated ones (Figures $5 \mathrm{~b}$ and $5 \mathrm{~d}$, respectively), it can be seen that coatings look distinctively different, depending on the type of substrate used. It appears from the images that the deposition of bismuth tungstate coatings onto PC500 anatase titania particles resulted in uniform coverage of the particles, while for the rutile particles, bismuth tungstate can be seen in the form of small clusters on the particles surface. This can be explained by the size difference of the two 
different types of titania and hence the difference in their dynamics of movement in the oscillating bowl during deposition. Additionally, crystal planes were identified from the lattice fringes of HRTEM images. For anatase titania, in accordance with the XRD data, lattice fringe spacings were estimated as $0.35 \mathrm{~nm}$, which corresponds to the (101) plane of anatase titania (JCPDS: 21-1272). For rutile titania fringe spacings were estimated as $0.32 \mathrm{~nm}$, which corresponds to the (110) plane of rutile titania (JCPDS: 21-1276). A representative HRTEM image of coated titania is shown in Figure 5e (sample A2); the fringe spacing was ca. $0.315 \mathrm{~nm}$, which can be attributed to the (131) plane of bismuth tungstate; $\mathrm{Bi}_{2} \mathrm{WO}_{6}$ (JCPDS: 39-256). It is worth noting that the as-deposited bismuth tungstate was in crystalline form, without any further thermal treatment applied to the samples. While no significant differences could be seen between TEM images of samples with Bi/W ratios of 4.5:1 and 2:1, the some deposits of amorphous tungsten oxide (as identified by EDX) could be seen on the HRTEM images of tungsten-rich samples (Bi/W ratio of $1 / 1)$. The example of amorphous tungsten oxide deposit is shown in the Figure $5 \mathrm{f}$.
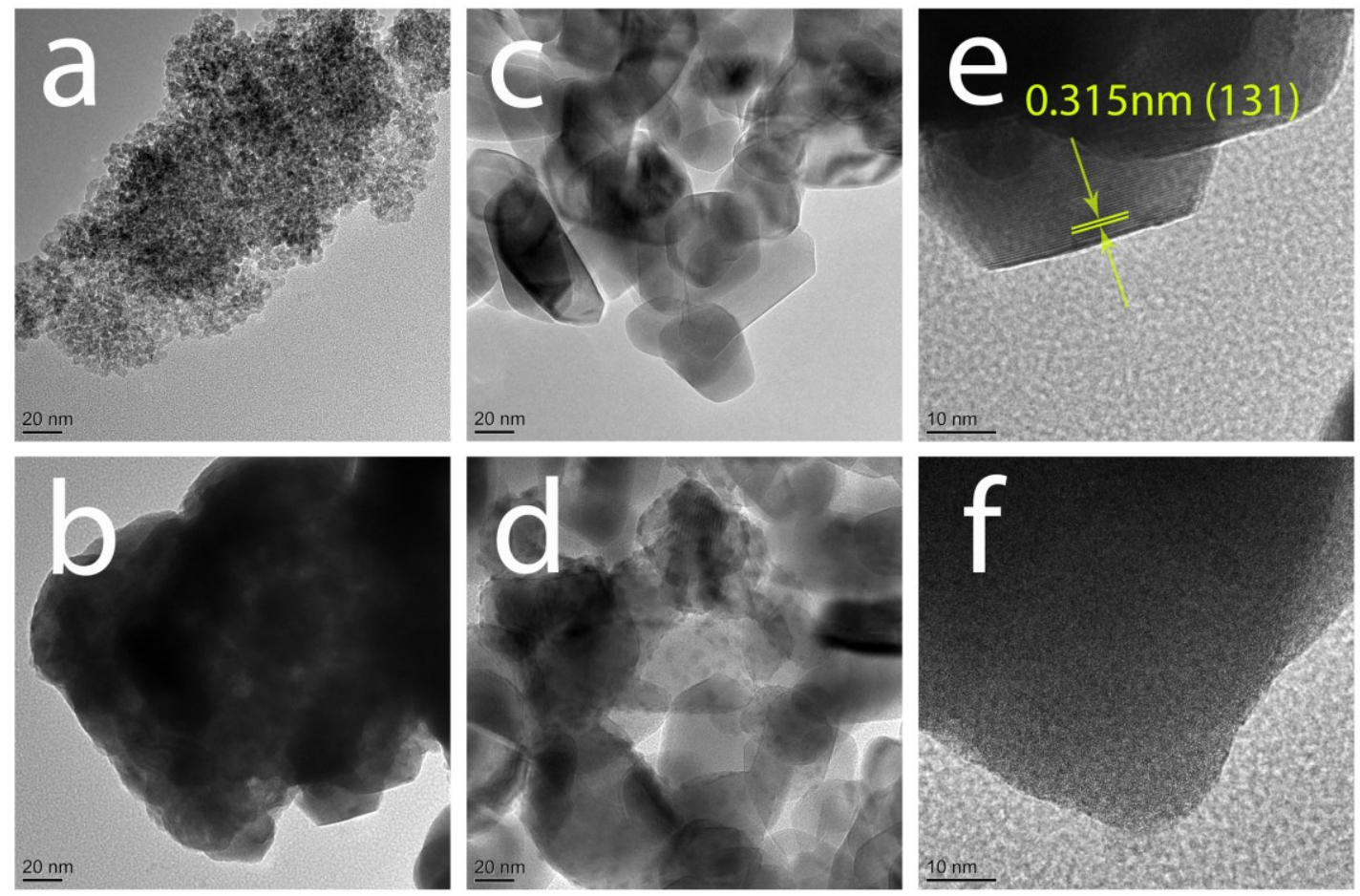

Figure 5. a-TEM image of uncoated anatase PC500 titania; $b$ - TEM image of bismuth tungstate-coated anatase PC500 titania (sample A2); c - TEM image of uncoated rutile titania; $d$ - TEM image of bismuth tungstate-coated rutile titania; $e$ - HRTEM image of sample A2; $f$-HRTEM image of amorphous tungsten oxide deposit (sample A3)

\subsection{Photocatalytic activity assessment (acetone degradation)}

Acetone is a model pollutant extensively used for photocatalytic activity assessment, because of its ease of mineralisation without the formation of gaseous intermediates [9].

As the surface areas of the anatase and rutile powders differed significantly, the amount of sample used to attempt to degrade $1 \mathrm{ml}$ of acetone was varied 
depending on the substrate used ( $1 \mathrm{~g}$ for anatase and $10 \mathrm{~g}$ for rutile powders). It should be noted here that the aim of the study was not to compare the photocatalytic performance of coated anatase to coated rutile, rather to investigate the effect of bismuth tungstate coatings on each of these types of $\mathrm{TiO}_{2}$. The plot of the regression curve of the natural logarithm of normalised $\mathrm{CO}_{2}$ concentration versus experiment time was approximately linear, indicating that the acetone degradation reaction followed pseudo-first order kinetics. The $\mathrm{CO}_{2}$ evolution kinetics are presented in Figure 6 , in the form of $\ln \left(C_{t} / C_{t=0}\right)$ as a function of irradiation time, where $\mathrm{C}_{\mathrm{t}}$ is $\mathrm{CO}_{2}$ concentration at time $\mathrm{t}$, and $\mathrm{C}_{\mathrm{t}=0}$ is the $\mathrm{CO}_{2}$ concentration at the beginning of the experiment. Additionally, first order rate constants were calculated from the gradients of $\mathrm{CO}_{2}$ evolution graphs and normalised per unit of surface area, for ease of comparison; the results are presented in the Table 2 . Additional tests were carried out without the presence of photocatalyst, as well as with anatase PC500 and rutile titania in the dark - no detectable $\mathrm{CO}_{2}$ evolution was recorded for either of these experiments.
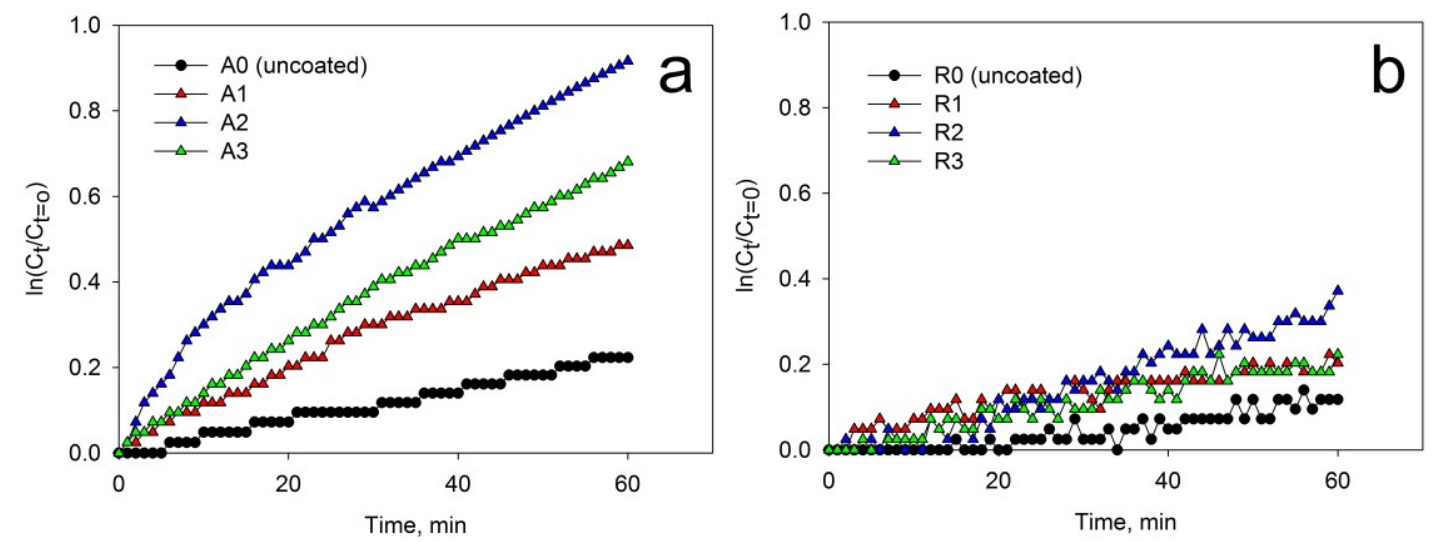

Figure 6. $\mathrm{CO}_{2}$ evolution kinetics in contact with bismuth tungstate-coated and uncoated titania samples under visible light irradiation; $a$ - anatase PC500 titania substrate; $b$-rutile titania substrate

From the $\mathrm{CO}_{2}$ evolution graphs given in Figure 6, it is clear that deposition of bismuth tungstate onto titanium dioxide particles resulted in significant increases of photocatalytic activity under visible light irradiation. As expected, due to the relatively high estimated band gap values of the uncoated anatase and rutile powders, their photocatalytic performance was quite low. It is evident that of the samples studied, the highest $\mathrm{CO}_{2}$ evolution rate was recorded for samples $\mathrm{A} 2$ and $\mathrm{R} 2$. It can be seen that with further decreases of $\mathrm{Bi} / \mathrm{W}$ ratio (samples A3 and R3), there is a significant decrease in photocatalytic activity, possibly due to the fact that, according to the TEM data, some amorphous tungsten oxide was present in the tungsten-rich samples.

However, from the results of the acetone degradation tests it is not yet clear whether the increase in photocatalytic activity under visible light for coated powders is solely due to the band gap narrowing, or that the deposition of bismuth tungstate also resulted in extended lifetimes of photogenerated charge carriers, compared to uncoated titanium dioxide. Therefore, a microwave cavity perturbation technique was employed to study the dynamics of the photogenerated charge carriers.

\subsection{Microwave cavity perturbation (charge carrier dynamics)}


The shifts in cavity microwave power for coated and uncoated titania particles are given in Figures $7 \mathrm{a}-\mathrm{b}$, for anatase and rutile titania, respectively. The data shown relate to the response of the titania particles to changes of the microwave power. As the changes in microwave power are proportional to the changes in conductivity, due to the production of the free charge carriers [34], higher values of microwave power attenuation mean that more active species are generated when powder is exposed to the light. From the data depicted in Figure 7, it can be seen that charge carrier generation is almost fully suppressed in uncoated anatase and rutile powders, which would be expected due to the relatively high band gap values of uncoated titania. However, all of the bismuth tungstatecoated anatase samples exhibited greater charge carrier generation, compared to uncoated PC500 titania, while for rutile powders higher carrier generations rates were seen only for samples R2 and R3, while sample R1 showed very low changes in microwave power, comparable to those of the uncoated rutile particles. Despite higher rates of charge carrier generation in the light-on cycle, rapid recombination rates of the charge carriers can be seen for samples $A 1, A 3$ and R3 after switching the light off. However, samples A2 and R2, with bismuth to tungsten ratios of 2:1, clearly exhibit different dynamics of charge carrier generation and relaxation, compared to the rest of the samples studied. It is evident that the deposition of bismuth tungstate with this elemental ratio resulted in much higher values of attenuated power, suggesting larger numbers of free charge carriers being produced during the irradiation cycle. Moreover, even 15 min after switching off the light source, large number of charge carriers still persist in samples A2 and R2. It is known that the separation efficiency of free charge carriers is an extremely important factor for enhancing photocatalytic activity. Therefore, the higher photocatalytic activity of samples A2 and R2 in terms of acetone degradation can be partly attributed to the longer lifetime of photogenerated charge carriers, rather than simply to the band gap narrowing.
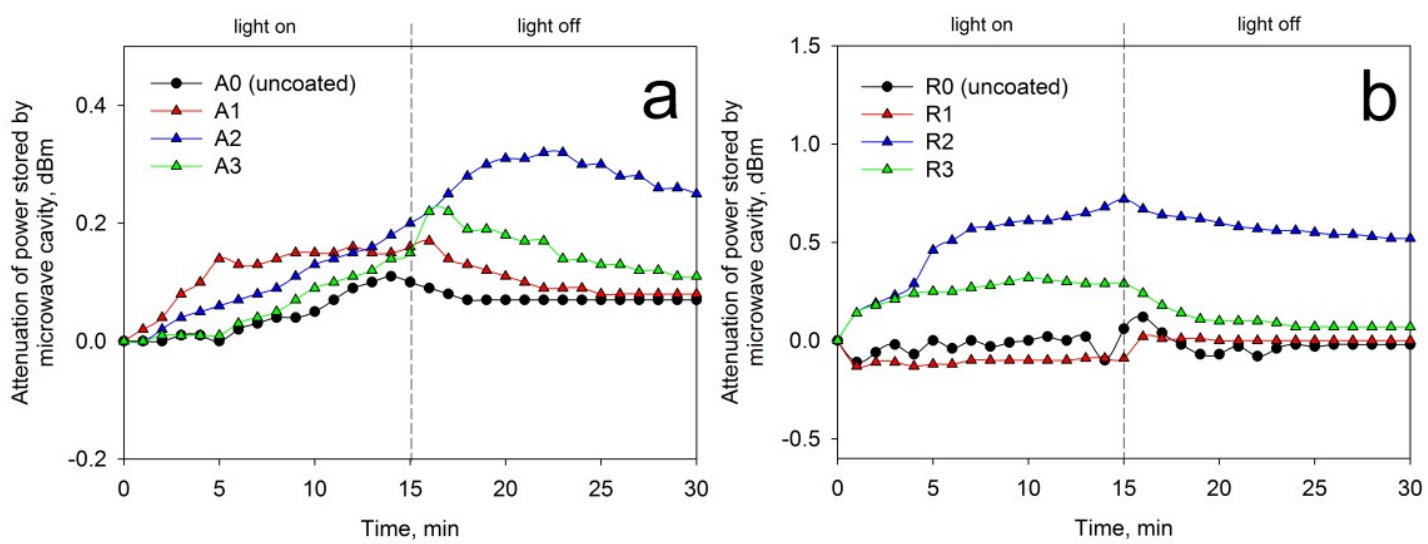

Figure 7. Shifts of the microwave power for coated and uncoated titania powders during consecutives periods of light exposure and darkness under visible light; $a$ - anatase PC500 titania substrate; $b$ - rutile titania substrate.

Furthermore, the distinctively different charge carrier dynamics of samples A2 and R2, along with their higher photocatalytic activity, implies that, as well as lowering the band gap of $\mathrm{TiO}_{2}$ and extending the lifetime of photogenerated charge carriers, bismuth tungstate coatings at $\mathrm{Bi} / \mathrm{W}$ atomic ratios of $2: 1$ possess intrinsic photocatalytic properties. This finding is in line with the earlier results 
for reactive magnetron-sputtered bismuth tungstate coatings deposited onto flat amorphous substrates [29], where the photocatalytic activity for Bi/W of 2:1 was found to be superior to the coatings with different $\mathrm{Bi} / \mathrm{W}$ ratios, even if the latters band gaps were lower.

\section{Conclusion}

Composite materials based on commercially available anatase and rutile titania particles and bismuth tungstate coatings were produced by pulsed DC reactive magnetron sputtering. The ratio of bismuth / tungsten was varied by varying the power applied to the targets. The use of an oscillating bowl mechanism enabled deposition of the coatings onto powders. It should be noted that the deposited bismuth tungstate coatings were crystalline without any further thermal treatment applied. It was shown that deposition of bismuth tungstate onto titania results in higher levels of visible light-responsive activity of acetone degradation, compared to uncoated titania particles. In addition, the deposition of bismuth tungstate resulted in band gap narrowing and extended lifetime of photogenerated charge carriers, according to the data obtained by a microwave cavity perturbation method. Of the samples studied, the best photocatalytic efficiency was obtained for the samples with a $\mathrm{Bi} / \mathrm{W}$ ratio of $2: 1$, regardless of the type of titania substrate used. Overall, deposition of bismuth tungstate onto titania particulates by reactive magneton sputtering appears to be a promising method of enhancing the visible light photocatalytic activity of commercially available photocatalytic materials.

\section{Acknowledgements}

This research did not receive any specific grant from funding agencies in the public, commercial, or not-for-profit sectors.

Acknowledgement to Leeds EPSRC Nanoscience and Nanotechnology Research Equipment Facility (LENNF) for conducting the TEM analysis of the coatings.

\section{References}

[1] F. Moulis, J. Krýsa, Photocatalytic degradation of acetone and methanol in a flow-through photoreactor with immobilized $\mathrm{TiO}_{2}$, Res. Chem. Intermed., 41 (2015) 9233-9242.

[2] T. Ohashi, T. Sugimoto, K. Sako, S. Hayakawa, K. Katagiri, K. Inumaru, Enhanced photocatalytic activity of $\mathrm{Pt} / \mathrm{WO}_{3}$ photocatalyst combined with $\mathrm{TiO} 2$ nanoparticles by polyelectrolyte-mediated electrostatic adsorption, Catal. Sci. Tech., 5 (2015) 1163-1168.

[3] H. Sakai, Y. Kubota, K. Yamaguchi, H. Fukuoka, K. Inumaru, Photocatalytic decomposition of 2-propanol and acetone in air by nanocomposites of preformed $\mathrm{TiO}_{2}$ particles and mesoporous silica, J. Porous Mater., 20 (2013) 693699.

[4] J. Szanyi, J.H. Kwak, Photo-catalytic oxidation of acetone on a $\mathrm{TiO}_{2}$ powder: An in situ FTIR investigation, J. Mol. Catal. A: Chem., 406 (2015) 213-223. 
[5] L. Ren, Y. Li, J. Hou, J. Bai, M. Mao, M. Zeng, X. Zhao, N. Li, The pivotal effect of the interaction between reactant and anatase $\mathrm{TiO}_{2}$ nanosheets with exposed $\begin{cases}0 & 0\end{cases}$ 1 ) facets on photocatalysis for thephotocatalytic purification of VOCs, Appl. Catal. B, 181 (2016) 625-634.

[6] I. Jansson, S. Suárez, F.J. Garcia-Garcia, B. Sánchez, Zeolite-TiO2 hybrid composites for pollutant degradation in gas phase, Appl. Catal. B, 178 (2015) 100-107.

[7] T. Tsuru, T. Kan-no, T. Yoshioka, M. Asaeda, A photocatalytic membrane reactor for VOC decomposition using Pt-modified titanium oxide porous membranes, J. Membr. Sci. , 280 (2006) 156-162.

[8] M. Mao, Y. Li, J. Hou, M. Zeng, X. Zhao, Extremely efficient full solar spectrum light driven thermocatalytic activity for the oxidation of VOCs on OMS-2 nanorod catalyst, Appl. Catal. B, 174-175 (2015) 496-503.

[9] M. Le Bechec, N. Kinadjian, D. Ollis, R. Backov, S. Lacombe, Comparison of kinetics of acetone, heptane and toluene photocatalytic mineralization over $\mathrm{TiO}_{2}$ microfibers and Quartzel® mats, Appl. Catal. B, 179 (2015) 78-87.

[10] S. Murcia-López, M.C. Hidalgo, J.A. Navío, Degradation of Rhodamine B/Phenol Mixtures in Water by Sun-Like Excitation of a $\mathrm{Bi}_{2} \mathrm{WO}_{6}-\mathrm{TiO}_{2}$ Photocatalyst, Photochem. Photobiol., 89 (2013) 832-840.

[11] I. Dhada, P.K. Nagar, M. Sharma, Challenges of $\mathrm{TiO}_{2}$-Based Photooxidation of Volatile Organic Compounds: Designing, Coating, and Regenerating Catalyst, Ind. Eng. Chem. Res., 54 (2015) 5381-5387.

[12] K. Chen, L. Zhu, K. Yang, Tricrystalline $\mathrm{TiO}_{2}$ with enhanced photocatalytic activity and durability for removing volatile organic compounds from indoor air, J. Environ. Sci., 32 (2015) 189-195.

[13] M. Ratova, P.J. Kelly, G.T. West, I. Iordanova, Enhanced properties of magnetron sputtered photocatalytic coatings via transition metal doping, Surf. Coat. Tech., 228, Supplement 1 (2013) S544-S549.

[14] M. Ratova, G. West, P. Kelly, Optimization Studies of Photocatalytic Tungsten-Doped Titania Coatings Deposited by Reactive Magnetron CoSputtering, Coatings, 3 (2013) 194-207.

[15] S. Rehman, R. Ullah, A.M. Butt, N.D. Gohar, Strategies of making $\mathrm{TiO}_{2}$ and $\mathrm{ZnO}$ visible light active, J. Hazard. Mat., 170 (2009) 560-569.

[16] R. Asahi, T. Morikawa, T. Ohwaki, K. Aoki, Y. Taga, Visible-Light Photocatalysis in Nitrogen-Doped Titanium Oxides, Science, 293 (2001) 269271.

[17] Z. Wang, Q. Xu, T. Meng, T. Ren, D. Chen, Preparation and Characterization of CdS/TiO2-Mt Composites with Enhanced Visible Light Photocatalytic Activity, Energy Environ. Focus, 4 (2015) 149-156.

[18] Y. Yamin, N. Keller, V. Keller, W03-modified TiO2 nanotubes for photocatalytic elimination of methylethylketone under UVA and solar light irradiation, J. Photochem. Photobiol. A, 245 (2012) 43-57.

[19] J.F. Zhang, Y. Wang, C.P. Yu, X. Shu, L. Jiang, J.W. Cui, Z. Chen, T. Xie, Y.C. Wu, Enhanced visible-light photoelectrochemical behaviour of heterojunction composite with $\mathrm{Cu}_{2} \mathrm{O}$ nanoparticles-decorated $\mathrm{TiO}_{2}$ nanotube arrays, $\mathrm{New} \mathrm{J}$. Chem., 38 (2014) 4975-4984.

[20] T. Saison, P. Gras, N. Chemin, C. Chanéac, O. Durupthy, V. Brezová, C. Colbeau-Justin, J.-P. Jolivet, New Insights into $\mathrm{Bi}_{2} \mathrm{WO}_{6}$ Properties as a VisibleLight Photocatalyst, J. Phys. Chem. C, 117 (2013) 22656-22666. 
[21] L.-W. Zhang, Y.-J. Wang, H.-Y. Cheng, W.-Q. Yao, Y.-f. Zhu, Synthesis of Porous $\mathrm{Bi}_{2} \mathrm{WO}_{6}$ Thin Films as Efficient Visible-Light-Active Photocatalysts, Adv. Mater., 21 (2008) 1286-1290.

[22] F. Deng, Y. Liu, X. Luo, D. Chen, S. Wu, S. Luo, Enhanced photocatalytic activity of $\mathrm{Bi}_{2} \mathrm{WO}_{6} / \mathrm{TiO}_{2}$ nanotube array composite under visible light irradiation, Sep. Purif. Technol., 120 (2013) 156-161.

[23] J. Xu, W. Wang, S. Sun, L. Wang, Enhancing visible-light-induced photocatalytic activity by coupling with wide-band-gap semiconductor: A case study on $\mathrm{Bi}_{2} \mathrm{WO}_{6} / \mathrm{TiO}_{2}$, Appl. Catal. B, 111-112 (2012) 126-132.

[24] Y.-F. Hou, S.-J. Liu, J.-h. Zhang, X. Cheng, Y. Wang, Facile hydrothermal synthesis of $\mathrm{TiO}_{2}-\mathrm{Bi}_{2} \mathrm{WO}_{6}$ hollow superstructures with excellent photocatalysis and recycle properties, Dalton Trans., 43 (2014) 1025-1031.

[25] Y. Zhang, L. Fei, X. Jiang, C. Pan, Y. Wang, Engineering Nanostructured $\mathrm{Bi}_{2} \mathrm{WO}_{6}-\mathrm{TiO}_{2}$ Toward Effective Utilization of Natural Light in Photocatalysis, J. Am. Ceram. Soc., 94 (2011) 4157-4161.

[26] G. Zhao, S. Liu, Q. Lu, F. Xu, H. Sun, J. Yu, Synthesis of $\mathrm{TiO}_{2} / \mathrm{Bi}_{2} \mathrm{WO}_{6}$ nanofibers with electrospinning technique for photocatalytic methyl blue degradation, J. Sol-Gel Sci. Technol., 66 (2013) 406-412.

[27] Q.C. Xu, D.V. Wellia, Y.H. Ng, R. Amal, T.T.Y. Tan, Synthesis of Porous and Visible-Light Absorbing $\mathrm{Bi}_{2} \mathrm{WO}_{6} / \mathrm{TiO}_{2}$ Heterojunction Films with Improved Photoelectrochemical and Photocatalytic Performances, J. Phys. Chem. C, 115 (2011) 7419-7428.

[28] P.J. Kelly, R.D. Arnell, Magnetron sputtering: a review of recent developments and applications, Vacuum, 56 (2000) 159-172.

[29] M. Ratova, G.T. West, P.J. Kelly, Photocatalytic visible-light active bismuth tungstate coatings deposited by reactive magnetron sputtering, Vacuum, 115 (2015) 66-69.

[30] M. Ratova, P.J. Kelly, G.T. West, L. Tosheva, A novel technique for the deposition of bismuth tungstate onto titania nanoparticulates for enhancing the visible light photocatalytic activity, Coatings, In press (2016).

[31] R. Pal, K.-H. Kim, Y.-J. Hong, E.-C. Jeon, The pollution status of atmospheric carbonyls in a highly industrialized area, J. Hazard. Mat., 153 (2008) 1122-1135. [32] R. Janes, M. Edge, J. Robinson, J. Rigby, N. Allen, Microwave photodielectric and photoconductivity studies on titanium dioxide exposed to continuous polychromatic irradiation; Part II:: Correlation of the microwave response with changes in sample microstructure during milling, J. Photochem. Photobiol. A, 127 (1999) 111-115.

[33] M. Edge, R. Janes, J. Robinson, N. Allen, F. Thompson, J. Warman, Microwave photodielectric and photoconductivity studies on titanium dioxide exposed to continuous, polychromatic irradiation Part I: A novel analytical tool to assess the photoactivity of titanium dioxide, J. Photochem. Photobiol. A, 113 (1998) 171180.

[34] J. Verran, G. Sandoval, N.S. Allen, M. Edge, J. Stratton, Variables affecting the antibacterial properties of nano and pigmentary titania particles in suspension, Dyes Pigm., 73 (2007) 298-304.

[35] M.P. Seah, C.A. Clifford, F.M. Green, I.S. Gilmore, An accurate semi-empirical equation for sputtering yields I: for argon ions, Surf. Interface Anal., 37 (2005) 444-458. 
[36] M. Ratova, P. Kelly, G. West, X. Xia, Y. Gao, Deposition of Visible Light Active Photocatalytic Bismuth Molybdate Thin Films by Reactive Magnetron Sputtering, Materials, 9 (2016) 67.

[37] N.N. Tušar, V. Kaučič, N.Z. Logar, Chapter 15 - Functionalized Porous Silicates as Catalysts for Water and Air Purification A2 - Suib, Steven L, in: New and Future Developments in Catalysis, Elsevier, Amsterdam, 2013, pp. 365-383. [38] A.F. Khan, M. Mehmood, S.K. Durrani, M.L. Ali, N.A. Rahim, Structural and optoelectronic properties of nanostructured $\mathrm{TiO}_{2}$ thin films with annealing, Mat. Sci. Semicon. Proc., 29 (2015) 161-169.

[39] X. Chu, G. Shan, C. Chang, Y. Fu, L. Yue, L. Zhu, Effective degradation of tetracycline by mesoporous $\mathrm{Bi}_{2} \mathrm{WO}_{6}$ under visible light irradiation, Front. Environ. Sci. Eng., (2014) 1-8.

[40] F. Amano, K. Nogami, B. Ohtani, Enhanced photocatalytic activity of bismuth-tungsten mixed oxides for oxidative decomposition of acetaldehyde under visible light irradiation, Catal. Commun., 20 (2012) 12-16. 